\title{
Literature and Art Therapy, as an Applied Model Used by Restorative Justice - Case Study: Minors at Kavaja Minors Institution in Albania
}

\author{
Dr. Edlira Macaj \\ Lecturer, \\ Tirana University, \\ Tirana, Albania \\ Dr. Marisa Kerbizi \\ Lecturer, \\ "Aleksander Moisiu" University, \\ Fakulteti i Edukimit, Godina nr.1, Kampus, Spitalle, \\ Durres, Albania
}

DOI: https://doi.org/10.36941/jesr-2021-0o3o

\section{Abstract}

\begin{abstract}
The purpose of this paper is to analyze the restoration process of juveniles who are serving their sentences at Kavaja Minors Institution, through the therapy of literature and art. In order to understand the process, it is essential to answer the following questions: does art therapy have a transformative effect on the psychology of adolescents who have problems with the law? If so, how and to what extent does it affect and by what means do we measure the result? Methods that were used in order to process the data were the empirical, analytical, comparative and descriptive ones. The data were registered before and after sixteen therapeutic sessions that were essentially related to reading literature and dealing with other arts. If art therapy is utilized through a structured program to ensure informal education (ie, discovering oneself and others by creating and practicing process), it may help to improve adolescents' behaviors. Juveniles that are in re-education institutions may even ameliorate their psychological conditions if they are engaged to literature and art therapy. Art in itself deals with the personal dimension and consequently the interpersonal one, giving minors the opportunity to self-heal and later to self-regulate. The findings of this case study justify the importance of art therapeutic sessions in transforming and improving behaviors, learning and commitment to the creative process. This therapy was difficult to implement during the closure of institutions due to COVID-19. As a result, some of the therapeutic sessions were performed virtually and indirectly. Literature and art therapy improves young people emotionally, mentally and promotes their artistic skills. Their creativity and artistic performance (poetry, essays, debate, drama, role-play, dance and singing) remain an important proof of this restoration process.
\end{abstract}

Keywords: literature, arts, medium, restoration, model, educational activities

\section{Introduction}

In the justice system, restorative justice for young people who have legal offenses is recognized as the initiator of building cooperative bridges between restoration as a process on the one hand and punishment as a fact for offense on the other. It is effective especially in young people, with whom 
models inspired by different practices can be applied. (Shapland, J., 2013). In Albania, restorative justice started its application after the '9os and it is reaching success in certain social categories, mainly in minors. The object of this paper is to analyze the restorative model which activates therapy through art and literature for transformative actions to juveniles who are specifically serving their sentence at Kavaja Minor Institution.

During this restoration process literature and art are used as educational alternatives; adolescents will understand why it should be read and what or how much they can benefit from reading in the specifics of a therapy (why and for what this therapy is needed). Thanks to a concrete program implemented in details, minors can understand that through reading they may know themselves better; they may even discover hiden secrets of self; may better understand social problems looking at similar narrative schemes, nurturing some personal skills, etc. Creativity and cooperation in the group play an important role in a therapeutic initiative, which was scheduled in 16 sessions, a part of which were conducted online, due to the protocol of Covid- 19 (March-June sessions)

These therapeutic sessions were based on several topics starting with reliability and confidentiality which are really important for the transformational processes in young people. Secondly, the topic "Art of Communication as a restorative technique" takes into considerations the possible transformation through the reading process, orienting minors through the culture of conversation, verbal interaction and group collaboration. Poetry and its inspiring role was the chosen topic of the third session. During adolescence it is typical to switch from concrete to abstract thinking. Judgment and critical thinking take place in this period of time, states Blos. (Blos, P., 1962: 12). The session dedicated to the topic "Literature and film as restoration media" starts with the famous novels turned into films and it continues with the comparison of these transformations. Poetry and painting for minors is done with the help of images of "a bridge between the body and the mind, or between the conscious levels of information processing the physiological changes in the body" (Lusebrink, V., 1990: 218). Thus the perception of images and the converting of such images into ideas, reveals the refraction of information and sensitivity of creation during the sessions. Description and detail as emotional liberation, multimedia, epistolary voice as narrator of subjective truths, quotations, reflective texts become the object of sessions starting with the seventh one, which served as the modality for the following sessions which due to the Covid-19 pandemic could not be direct. Self-reference and selfconfession through creation was seen as an alternative to relating oneself to personal problems or concerns. From the ninth session to the end, the juvenile became the main protagonists of the selfrealization of their creations through artistic performances. These sessions resulted at being very productive related to poetry, paintings, awareness messages, choreography, traditional dances and acting as well. The last session was dedicated to the laughter and positive energy that it gives especially to motivate their age. It was treated as a motivating structure for their sensitivity.

\section{Literature Review}

The term 'art as therapy' coined by Kramer, was used with the premise that the artistic process itself allowed the individual to re-create essential experiences and feelings, thus offering the possibility of "re-evaluating, resolving and integrating conflict". (Rubin, JA, 2001: 280). Literature and other arts in this case study are referred to as media with great restorative potential in adolescents. Literature itself is considered to be as a conductor of values and education. However it may becomes functional only if it is addressed to juveniles through a carefully guided reading, through which we can act concretely in order to facilitate their transformation. The interaction of literature with other arts, the clarification of their connection and functional context can become concrete tools to discover, among other things, the artistic abilities of minors.

Literature, as a creative expression will exist, it will even surpass itself. (Klarer, M., 2004). Today the concept around it is related to its uniqueness as a creative work through its medium, language, ie literature as a fusion of language (Culler, J., 2001: 37). Man remains at the core of literature remains, along with his experiences and the relationships he builds with himself and others. But every art has 
this essence, only that their broadcast media differ depending on the expressive character of the art itself. All arts are expressions or applications of human creative skills and imagination, producing works to be appreciated primarily for their beauty and secondly for their emotional power. Dissanayake thinks that arts play an integral part of social life. According to her, art should be understood as a universal human wealth. To her, art is something that people do and feel (Dissanayake, E., 1990: 8)

Literature maintains strong connections with other arts. If we recall the categorical elements of literature, according to Pound, such as melopoeia, phanopoeia, logopoeia (Pound, E., 1960), we can add that literature carries these other arts within itself. It remains both a separate art and an inclusive one. On this giving and receiving process between arts we have assertions from antiquity, as Simonid said: poetry is like a painting that speaks, while painting is like a poem without words, or Horace who said: Ut picture poesis. If literature dexterizes expression, painting shapes colors and sculptures forms. The intensity of the literary description helps in the perception and creation of a new color or form. Numerous literary works have inspired other works in painting, sculpture, etc.

It is exactly the use of strong links between literature and painting (even calligraphy as an artistic genre) that is an important choice in this therapy for transformation through the use of both arts. On the other hand, it is enough to remember how many poems have turned into songs, or how folk creativity has also influenced the birth of various dances. Famous poetic texts have turned into lyrics for famous songs and on the other hand narrative texts have turned into great cinematographic successes. Even today literature alone or fused with other arts, remains the human alter ego by significantly improving it mentally and emotionally.

The same give and take relationship exists between literature and several other study disciplines, the focus of which is man himself. Thus literature is closely related to philosophy, as both are in search of truths: one aesthetic (fictional one), the other the metaphysical one. Although at risk of confusion with each other in certain types of writing, it is worth experiencing this type of risk, says Hartman. (Hartman, G., 1979: 9) Another connection exists between literature and other research fields, such as sociology or psychology. The common human object is viewed from different points of view. Historical, social context and internal personal motivations build a new relationship among them.

All these connections between the arts and disciplines searching for man, his situations, or the search to discover his inner self have served as a theoretical support to successfully implement the idea of a process for transformation in the category of juveniles, through art therapy.

This intercorrelated concept of literature helps us in our special approach when we use literature as a medium of restoration. Literature as a basic component of restorative therapy in juveniles restrengthens its universal character, influencing human education. Only through evil one can understand the good and vice versa, through beauty one can acknowledge ugliness, etc. Literature thus produces endless discussions in its dialectic. In every literary work, the reader finds himself or part of it, finds every human being. (Macaj, E., 2019: 32) Through a reading / re-reading, creation / re-creation the artistic work is enjoyed, and at the same time it stimulates the next act in creation. The young reader, whoever he is becomes potentially the next creator. So there is a close connection between creativity and therapies. The latter reveals in specific circumstances this ability to the young reader and tries to nurture it through concrete examples.

The result of art therapies has the specificity of its measurement, mainly in the personal dimension of those who participate in these therapeutic exercises. Art therapy is based on the idea that the creative process is a healing process and improves life and is a form of nonverbal communication of thoughts and feelings (Malchiodi, C., 2003: 1).

Many studies prove that long-term art therapies have been effective in promoting cognitive and emotional development, in regulating relationships but also reducing destructive behaviors in adults and children. (Alders \& Levine-Madori, 2010) These achievements are also claimed by this art therapy.

In the therapy of literature an important role is played by creativity which requires the activation of the imagination and the embodiment of innovative ideas. Creativity involves the depth of a mind and many, many depths of the unconscious (Sacks, Oliver, 1998). Thus it is possible for art therapy to create a supportive environment and in this safe area, the individual can be encouraged to do a self- 
exploration, so such therapies can reveal things that one does not really know one has. Difficult cases are not excluded when man is faced with great personal problems and challenges, which have turned into art products of special importance.

Mental and spiritual balance is not always found in peace. Creativity is an important protective factor when facing difficulties and trauma (Wolin \& Wolin, 1993)

Periods of hardship require greater human attention. Therapies through the arts are a valuable treatment option. Various studies (Wood, 2011) suggest that art therapies improve issues related to the emotional realm. Others see the therapeutic process as effective in reflecting positive change (Uttley, L., 2015)

The American Organization of Art Therapy (2018) sees the effectiveness of these therapies in improving cognitive and sensory-motor functions, increasing self-esteem and self-awareness, cultivating the emotional aspect, spiritual enrichment, reducing or resolving conflict, and reducing stress as well as improving the social aspect, those which allow people to experience, and at the same time to express themselves through them.

Juveniles serving sentences at IMK Kavaja are there due to various circumstances. This therapy that covers different forms of personal expression and experience helps them to evaluate themselves in another aspect. The structured combination between art and therapy based on it helps individuals understand deep aspects of their own individuality (Case \& Dalley, 2004).

Therapies achieve their result through the implementation of a regular frequency of various artistic activities. Educational-artistic activities ensure their success through the engagement of leading staff: teachers, field experts, actors who facilitate the educational process in a given learning environment, with a method of guidance and interaction between parties. Activities should be interactive. Through them, communication should be organized and knowledge transferred to (students) or learning skills should be improved. The activities are different depending on the categories and their educational purpose. (...) making art can become a tool of self-expression and selfregulation, providing a unique opportunity to channel emotions and develop identity. (Gussak \& Virshup, 1997)

\section{Methodology}

The main practice for discovering the effective role of literature in restorative justice is that of interaction and practical expert-juvenile cooperation. Literature and art therapy here mainly considers the empirical method and interactivity as a follower of educational and corrective messages, through which concretizes the whole process that requires the fulfillment of several steps such as: 1. Observation which based on the way the sessions take place provides monitoring of directly, ie the step-by-step achievements of the juveniles according to the topics defined by the expert. 2. Organizing data where clues, topics, suggestions are given and data are collected on the concrete work of juveniles divided according to their skills in creativity and Assessment / Stimulation, which is about creating summaries of artistic achievements during the sessions. They are the very reflection of their spiritual and mental transformation.

The results of this venture are concrete, as the therapy of art and literature considers the inclusion of some concrete artistic forms such as: film performances, dramatizations, poems, readings, interpretations and creations, role-play, drawings, paintings and sculptures, singing, dancing, debating, elaborating critical thinking through essays, etc.

Tangible achievements (artistic products of minors) during 16 sessions justify the positive, rapid and tangible effect of this therapy on minors. This success also justifies the theory that art therapies are also considered as psychotherapy which centralizes art practices and interventions with conversations and counseling as the main modalities of treatment, or according to Naumburg the most basic human feelings. (Naumburg,1958: 511).

Due to the pandemic caused by Covid 19 and the limited situation of movements caused by it, the therapeutic sessions of literature and other arts foreseen to take place in the institution, were 
interrupted for a short period, to be reactivated through a new formula, that of exchanging information electronically, but also the technical assistance of KMI (Kavaja Minor Institution) staff. Organization of this type of therapy designed with a working group of experts in the field, assisted by students of sociology and social work and technically assisted by the staff of the institution, would not have been possible without the voluntary participation of all juveniles in the institution. Malchiodi (1998) states that: art therapy is based on the idea that every individual has the ability to express themselves creatively. For him the product is no more important than involvement in the process. Even in our initiative, it is not the aesthetic quality of the artistic products made by the minors that is important, but the need that they have to express themselves through art. What matters is their involvement and their desire to be liberated through art.

Meetings in IMK with the maximum participation of 23 juveniles (all boys) serving sentences in the institution, were organized regularly lasting about two and a half hours considering equal stay in specific divisions according to groups of juveniles (4-10 each group as it is a flexible number due to their sentence or new arrivals) This is also because large groups, especially in art therapies, become difficult to manage and achieve their goal. The literature and other arts therapy program covered the following areas:

- Interactive interaction sessions (literary creations and interpretation, socio-cultural debates, discussions on cinematographic art, etc.)

- Applied arts sessions - paintings, sculptures (handmade works), etc.

- Performance sessions - staging, role play, dramatizations, etc.

- Reflective, awareness-raising sessions - electronic media.

The therapy was developed in the framework of educational-artistic activities with topics set in cooperation, proposal and agreement with the juvenile. The modalities of development of each activity were different using direct or indirect platforms (digital, film), application through different communication technologies, sessions of exercises (such practices are popular when art therapy is done in groups) etc. Exercises related to perception, memory, self-discovery with the focus on numerous topics such as family connections, meditations, connections to other expressive arts and well-known and widely used models as well. These models are suggested by the researcher Liebmann, who is well acquainted with the field of restorative justice. (Liebman, M., 1986)

\section{Research Data: The Model implemented}

Literature integrated with other visual and applied arts manages to produce various forms of communication that transform the behaviors of minors. Direct practices with minors were applied including thematic sessions such as:

Reading. (bibliotherapy) During these sessions there were proposed well known literary passages during reading hours. Reading enriches the thought and it faciliates the process of creation of thematic essays used to promote universal values. Reading simultaneously enriches critical thinking and help the creation process. These practices are carried out in circumstances of spontaneity.

Painting (visual therapy). Teenagers who participated in the art therapy, were asked to take a selfportrait during painting sessions.

Ethics of communication. (verbal therapy) Debate sessions, conversations are really important because they help building the debate culture on various issues. They can also build a mechanism of their evaluation of how they conceive human values; what are the limitations and why they may display problems in such discussions. Scheduled sessions for debate on social issues or discriminatory issues reflect how teenagers feel, as well as they help to articulate issues like 'the other', diversity, etc.

Film and photographic art. (multimedia therapy) The description of a moment of photographic shooting or literary material screened for didactic purposes are important mediums by which juveniles can reinforce their system of evaluation, analysis, comparison and aesthetics. A photo collage can help illustrate their feelings and how they describe a situation.

Self-identification. (self-reflection therapy) Self-discovery and reflection sessions on identity and 
personal motivations are useful tools because self-confession, self-description play a very important role in defining freedoms, restrictions, duties and rights.

Integration of literature with electronic media. A visual diary is an alternative way to express teenagers' feelings. Drama therapy, which is considered both a creative and an interpretive session (due to improvisations), is one of the well-known forms of art therapies too. Even in this case it had obvious results with the performance commitment of the juveniles themselves.

Miscellanea - are the therapeutic sessions, in which there is room for spontaneous requests that minors had when faced with discussions, reflections, works that require the mixing of certain artistic forms. Story-telling or anecdotes are one of these effective interventions. Therapeutic writing on the other hand was an approach that yielded results in: relieving stress, discovering painful problems and feelings, establishing connections between feelings and behavior, and much more. Adolescents mostly wrote about painful experiences that were difficult to discuss.

The practical results after the sessions that foster creativity were easily visible. Hardy states that when you are working with teenagers, therapy should focus on creativity. (Hardy, K., 1996: 55) These practical results during the therapy of literature, are documented through: their literary creations with which they expressed themselves: drawings, paintings. At the same time the drawing process became reflective.

16 different therapeutic sessions were developed with the aim of cooperation, confidentiality, trustworthiness, artistic stimulation and their restoration in behaviors, thoughts, and decisions.

\subsection{Reliability and confidentiality}

In the first sessions of therapies of this kind, the restorative journey begins with the construction of bridges of communication between the working group and juveniles whose age is characterized by both emotional fluctuations and mood swings. Gussak, in his paper, Art Therapy in Prisons and Other Correctional Facilities, highlights the great importance of the structuring, channeling of art to the categories of individuals in these institutions. First step was building the trust that should be established between the parties. Art therapy for him goes through the psychological, psychotherapeutic and counseling aspect. These types of therapies develop an understanding of their identity. (Gussak \& Virshup, 1997) Thanks to the proposed strategy which started with the recognition and presentation by both side of participants, the first cooperation between the different emotions of minors and the naturalness created thanks to the group of student assistants.

\subsection{The art of communication}

The second session of literature and art therapy with minors at the Institutions took place on February 1st, 2020 with the participation of the expert and three young professionals. Since the juveniles were divided into small groups, the meetings were held specifically for each group, giving them equal time. The second session aimed to ensure the juveniles' attention to communication, ways, 'techniques' of speaking, etc. Studies have shown that adolescent therapies often begin their work with speech, as traditional therapeutic choices (Sommers-Flanagan and Sommers-Flanagan, 1997). For this reason the team planned to develop different scenarios regarding the art of conversation and communication in general. This educational aspect guided the juveniles in the culture of verbal communication. They could regard the latter as a constructive feature of personal attitudes and the formation of relationships with others. They were introduced to various tips for improving communication ethics to create models of constructive social behaviors both personally and interpersonally. This session aimed to train minors in the art of conversation, persuasion, reasoning, selection of words, etc.

In such sessions, sets of rules or principles conveyed theoretically, were not easily applicable. The art of speaking, reasoning and persuasion can serve minors in the same way, as was the organization of conversations which inadvertently start from the fragmentary conversation of sporadic. It continues to form an axis of ideas around the theme, purpose, conviction, etc., and end up with a series of 
conclusions as the case may be. This theory-free 'rhetoric' certainly helps juveniles to become selfaware of the power of speech and accept the other's point of view. Through this way, conversations become natural and not strained. Participation of juveniles in dynamic interventions reflected the flexibility of their personality towards such concrete proposals, from which they can benefit.

\subsection{Poetry}

The third therapy session considered the juvenile's suggestions for reading and interpreting selected poems by well-known national and international poets. The poems were selected by the working group and they were thematically focused on family, love and friendship. These topics were selected to get to know some of the personal and interpersonal aspects of the juveniles. The topic of the family included poetry about the mother, father and family in general in order to understand how strong the personal bond of each with their relatives was. However, it was not anticipated that the selected topic would have so much interest to them, given the fact that it is very difficult to read adolescents 'emotional reactions. The greatest achievements of this session were their personal confessions which exceeded all expectations. Their inclusion in the reading (interpretation) of each poem, made them see it differently and personalize the poem according to their feelings. Love, as an artistic topic was conceived in its broadest dimension, without restrictions of any kind. Love is a topic which accepts all the human emotions inside, both the smile and the sadness, the comic and the tragic, the feeling and the thought, the real and the surreal, the rational and the irrational, etc.

The session produced an energetic discussion regarding the perception of universal love by the juveniles themselves, a discussion which was also enriched by laughter and jokes between each other.

The third topic dedicated to friendship received subjective approaches in each of them. It was interesting to understand how different, although in similiar age groups, everyone's concept of friendship was. Friendship in them ranged from denial to sacrifice, from indifference to devotion, from chance to perseverance, and so on. The fact that juveniles stay for a relatively long time with each other, makes them get to know each other better, hence they speak without reservations due to close social relations they build. In the discussions of this session, interest in the poems related to family prevailed, especially given the circumstances that some of them did not have the family support. The first surprise result for the working group was a handmade application of four artistic flowers, which was accompanied by four poems created by the teens dedicated to the positive feelings that the first sessions of therapy brought in them.

\section{Literature and the movies}

The surprise of this session was the discovery that among the young people there were some teens who had read many books and the discussion with them was impressive. It was these minors who knew the books and movies inspired by them, were the ones who also expressed their desire to interpret literary texts and participate in theatrical performances. (they were mainly high school students) From this first idea the whole group decided to work with interpretations of monologues of famous book characters, which were applied in the next sessions; in addition to the seriousness with which the juveniles were prepared (EH; FM) they also produced a lot of hilarious situations.

Thus the drama therapy interwoven in several sessions, it started with interpretations and role exchanges, independent staging and recitations. Drama therapy has been known as art therapy since the early 1960s. It is now seen as the process of promoting health rather than solving problems of various natures (Jenings, S., 2009)

This session also started the preparation for exploring the connection between literature and the art of painting, a connection which has been extended to several sessions. The paintings and literary creations were used in almost every session and hey have resulted in the highest quality works during the whole therapy. During the session, the training group shared among the juveniles artistic and entertaining sets (canvas, painting colors, chess, etc.) which were needed for their artistic 
constellations.

During a therapy session, the interplay between the arts and other disciplines is one of the most successful methods to maintain the dynamics of the sessions, but what is most important is to maintain the interest of the juveniles. One of the most difficult things about working with teens is to nurture and maintain their curiosity about the program that is offered. During the breaks we used to have various games or psychological tests which were really popular to the team.

\subsection{Poetry and their painting-functionality in the transformation of young people}

This training session was dedicated to the visual image and its connection to poetry. All juveniles participated in the construction of the calligrams, recognizing the calligraphy as a creative and fun way to combine the painting with the words for a meaning that encompasses both. Each of them tried to create examples of calligrams. This exercise allowed them to travel with the imagination to obtain shapes and sketches accompanied by quotes or emotional statements but also to increase the intensity of expression within certain images.

One of the characteristics of art therapy is 'metaphor as a therapeutic tool'. Metaphorical images provide psychological insights beyond reasoning. For Moon visual metaphors provide interpretation and provoke the thought. (Moon, 2007: 4) In this session each calligram managed to summarize a personal picture of the feelings of the teens. So, one calligram was related to the lack of freedom; another with the reflection of an envelope, which carried the meaning of letter and longing, etc. Although the ideas were spontaneous, these instant creations were deeply appreciated because through them minors managed to reflect:

- Speed of reaction to the topic proposed on the spot, without prior knowledge.

- Quick understanding of the meaning of the concept and its conveyance into artistic works.

- The economy of words which are conveyed into an image, which requires a lot of concentration and patience

- Deepening in reasoning to link two categories together

The most dominant illustrations mainly involve the expression of the concept of freedom. One of the most representative cases was the figurative symbolic illustration of hands bounded by wires or that of animals outside the zoo, balloons to the sky, hearts and messages of hope, and so on.

\subsection{Description, detail - as emotional liberation}

Descriptions and details as special techniques of artistic expression focus on the reflective moment. Through the description the juveniles espress the opinion they have for each other but they also describe their current situation. Even the monologue, as a technique of narration, self-confession, etc., was seen as a way to transmit certain emotional states. Descriptions of each other, or descriptions related to other free topics were also synchronized with instant sketches and drawings. This session enabled specific identifications of their desires regarding artistic preferences.

\subsection{Multimedia-(feelings and thoughts)}

This session was conducted with the participation of fifteen remaining juveniles in the institution, grouped in two sectors. Due to the COVID-19 situation, the team of young professionals and experts could not directly conduct the session as planned. But other alternatives were considered and successfully implemented. The experts coordinated the work with the support of the institution and enabled the successful management of the planned program. The material prepared by the experts and consulted with the working group was provided to the juveniles as a presentation in Powerpoint format. Electronic presentations, as a new communication medium, took place for all sessions until the end of the project. The session was dedicated to poetic prose as an intermediate literary genre. This selection was made to enable juveniles to list their thoughts in prosaic form and to express their feelings or 
emotions in verse. Another alternative was to recreate the images obtained by the reading itself by testing their curiosity to challenge themselves on how to perceive the text as an image and what resonates with the symbolism of snow, sea, lake, mountain or rain, etc. This was a task to improve their emotional reflection and logical reasoning. This hands-on exercise helped juveniles to personalize information and influence on improving their imagination. Empathy makes individuals more tolerant in human relationships and this affects the behaviors between them. They also created texts and reflected on certain quotas that link the image with the thought. Some of them chose strength (mountain), tranquility (snow), mystery (sea), etc.

\subsection{Epistolary- therapy through self-confession}

It is very important to express thoughts and feelings towards a particular person. The minors enjoyed a video-montage specially prepared for this topic by the expert, in order to ease the communication process. The goal was how to say the things that concern us and in what easy ways; it can be done by revealing our important things through the story of love, friendship, respect, especially in atypical circumstances, when we can no longer have the loved ones around us.

Through the universal and well-known message of love for family, friends, our loved ones, minors were encouraged to appreciate connections with their people even when they are away, alone and separated. The minors were encouraged to write a personal message to someone and the attendance was very satisfying. Their heart-shaped lettering devotion (designed by them) focused unconditional love for their family members, as well as appreciation of friendship. This session proved very effective in opening up their spiritual dimension to promoting educational and motivating values such as love and friendship.

\subsection{Song and its role in restorative therapy}

This session with the participation of 16 minors connected the poetic texts with the songs. Most of the teens admitted that they knew the songs, but they had no knowledge that these famous songs were inspired by well-known poems of Albanian literature. The session became very interesting including all minors singing together. They successfully performed a structured and cheerful karaoke while improvising hip-hop variants and this performance made the session joyful and funny. In the end, they wrote messages inspired by the poems. The achievement of this session was the writing of their "anthem", created especially for this song therapy session by one of the minors. Song therapy has a rapid effect and remained one of the most meaningful sessions for the teens. Their text entitled "Our Anthem" had the following bridge: We have many rights, we will protect them... / We ask for your support, / To make it happen. The poetic text which was turned into a song, was created by the minor with the initials V.K.

\subsection{With literary and real characters}

The main discussion of this session was focused on psychological novels and literary characters who have had strong conflicts. Thus the boys could specifically discover a fictional psychological character and compare it to themselves if they were in similar circumstances as the fictional characters. If so, what would they have done? It was an interesting topic as most teens were involved in comparing the situations and of course the events of the novels, with their imaginary scenarios, if they were to find themselves in the shoes of the characters.

In art therapy, we try to make aesthetic expression a complement to self-expression in a person's relationships with others. Therapy in this case helps the juvenile, as Robbins asserts, in that process, the art therapist works to protect an individual's character and slowly helps him or her to emotionally overcome the full impact of symbolic communications. (Robbins, 2000: 23) Discussing similar situations extracted from popular novels, inspired the teens and developed their analytical skills. 


\subsection{Transforming youth through argumentative thinking}

The eleventh session took place in the presence of the fourteen remaining juveniles in the institution. The session was planned to guide the juvenile towards an inner perspective of thought. The work with the juvenile was directed in the form of a project which elaborated topics such as: man, ideal and material; the spiritual aspect, etc. These issues provoked the juvenile's reflection on core values or vanities, as well as on their inspiring model and philosophy, or their personal background. The finding of the session was impressive as all the juveniles were able to reflect on their dreams, regrets and inspirational patterns. At the end of the session dicussions were held about the sustainable human values and the teens graphically worked with some important quotations.

\subsection{Promoting values through awareness messages}

Session 12 which coincided with the participation of the remaining 12 juveniles in the institution focused on the potential that the individual has to contribute to the society. The experts encouraged juveniles to discuss the importance of the individual in society and especially the importance and place that families play in their lives. The focus of the session was related not only to the education towards core individual values but also seeking answers to the questions of what is and how can one build a relationship with another? How much does knowing yourself help you build strong relationships? How and where they imagine themselves after a few years. A special finding of the session was the awareness messages that young people had prepared about themselves and values in general. In this session they proved to be ready to freely describe themselves; they were also willing to talk about their identity, fears, weaknesses and inspirations.

\subsection{Restoration through rhetorical skills}

Session 13 of art and literature was devoted to the elaboration of rhetorical skills, for example: how to persuade another in a conversation? Persuasion as a technical skill helped juveniles to arrange and express their thoughts clearly and concisely on a given topic. In order to achieve their goal they had to link the discourse to facts. This kind of approach considers literature as a culture of debate supported by arguments. As such, through the elaboration of thought, it enables the individual to react to all the events of human life. It was this session where the juveniles expressed their argumentative skills to achieve persuasion in order to win in discourses started with some hypothetical situations. The juveniles in this session challenged each other in scanning and exchanging different roles and equally diverse views. The exchange of positions made them accept diversity and balance changes.

Through discussions about culture, in general, they expressed their views on things or events that they value most. One of the functions of art therapy is to develop in these young people independence and autonomy, by feeling responsible during the process. During the cycle the teens could learn, change, reflect and "recreate" themselves.

\subsection{Self-reflection therapy}

Session 14 took place with the remaining 12 juveniles in the institution. In the previous sessions, art and other mediums such as painting, singing, dancing, interpretation, improvisation, critical thinking, essay, poetry, reading, etc. were promoted. This session was dedicated to a specific topic such as: the personal world, which tested the ability of minors to express themselves through a personal artistic collage in visual forms, but also in verbal ones. All their personal achievements that they had realized during the literature therapy sessions were listed. By exploring their actual art (poetry, paintings, essays, etc.), they also identified their difference; their thoughts, emotions, and behaviors during this time.

This session was valuable in understanding the dimension of change within them. The files with 
the creations, works and contributions of any kind during the literature sessions reflected their transformation thanks to the treatment of many issues thanks to the artistic approach. For all teens there, the axiom was valid: if we want the big change as a whole, it has to start from the inner self, the personal side. In art therapies the creation of collage images was always accompanied by a decrease of negative mood. (Bell \& Robbins, 2007) Throughout the sessions of literary therapy there have been literary creations related to thematic peculiarities.

The most obvious part of their transformation is their quest to put themselves in social environment. The request not to be discriminated is an appeal that comes from themselves, as they have made a "mea culpa". One of the most representative texts of this internal transformation with a real and practical measure of oneself is the poetic text "Stop Discrimination" which was created by a minor in the institution (E.H.). It is a text created specifically to reflect their "journey", as well as to reevaluate their status in society. Stop discrimination!

\subsection{Self-identification - as an indicator of restoration in therapy}

Session 15 focused on familiarizing juveniles with the model of the future (such as lack, hope, purpose, goal, etc.). In this session a socio-cultural conversation was needed on the transformation and the maturation of an individual. In this session it was deemed necessary to propose a natural testing for juveniles that related to questions about themselves in the form of a self-assessment. The interview focused on three references: Who was I and how was I? Who am I now? Who will I be? This selfinvestigation revealed their current status. Their answers made a reflection of their soul and mind. At the same time they revealed their goals and their future design. Although in unusual circumstances the desires and projections of the future are nourished by the human motivation.

\subsection{Laughter and personal dedication - as concluding stops of art and literature therapy}

Session 16 was the final session held at IMK with juveniles. It was focused on the interaction of juveniles who showed expressive competencies. Experts decided to dedicate the session to the exploration of the most healing part of human life, which is laughter. In this therapy session it was evaluated as a positive indicator of human behaviors in society. During the meeting humorous stories and anecdotes were told. They were considered useful for therapy because through laughter people can react positively and come closer to each other.

Minors were free to interpret different life situations by shifting in hypothetical times, possible and impossible circumstances and spaces at the same time. Their wishes and future challenges were also discussed. The final discussion was devoted to their transformation journey during all sessions, as it started with communication ethics and ended with laughter, considering the last as emotional and mental relief.

Recent sessions have also had a dynamic verbal expressions by juveniles. Videos were made from them, with which all their energy was elaborated in function of educational topics. At the end of these sessions it became possible to create a film from the video-collage which explicitly synthesized the artistic products of the minors themselves in all the forms they could realise, including the execution of dances.

\section{Results}

- Literature and its fusion with other arts made the sessions of therapy very fruitful due to the cooperation based on mutual trust that was created between the working group and the minors themselves.

- This therapy, as one of the therapies used for restorative justice for the age group of minors, had positive effects in many aspects as the incentive of free creativity in accordance with the abilities of each teenager. 
- The creative works of minors, both literary and applied creations (handmade artistic works), justify the transformative effect of minors in creation, communication, interactivity, interpretation, argumentative thinking, etc.

- Therapy of art and literature promoted freedom in creativity, which is the most flexible and appropriate way for the characteristics of this age group. The artistic works of the minors during the engagement of the therapy sessions were numerous and some of them had very high quality due to the desire of the juveniles to actively participate in each session. The fact is that starting from the second session the transformative process was associated with artistic works.

- Therapy was successful in reducing anxiety and emotional difficulties, managing family and psychosocial problems as well as reducing stress. All these sensations and motions were reflected in their artistic works.

- The therapy was finalized with some other artistic products realized by the working group. A video-montage was created with the artistic materials of the young people of the institution, which reflected in a synthetic way:

- Their artistic products in literary creativity: poetry and essays;

- Understanging themselves by developing critical thinking;

- Coping with each other, and accepting diversity, thus developing communication ethics and debate culture;

- Entertainment through music, song and dance;

- Expressing their emotional world by showing socialization, belief in core civic values and acknowledging their weaknesses;

- Dedications to therapy education staff, showing the most optimal cooperation between the working group composed of experts and students in the field of Psychology, Sociology and Social Work.

\section{Conclusions}

The whole process and educational activities in art and literature therapy sessions have had a significant impact on juveniles as in almost every session it has reflected their thoughts and considerations. This therapy, among other things, provided the transforming mission to the juvenile in several directions:

First the therapy was very intensive and with a synergy between the working group and the juveniles themselves, who after first building trust with each other, engaged according to their abilities in each of the sessions planned in the educational program. The group has always been welcomed by the juveniles, creating a mutual trust and confidentiality between the parties.

Secondly, in creating a collaborative artistic climate with practical results, creative work according to individual skills (painting, creation, dramatic performance, song and dance, rhetoric, etc.) Starting from the third session of literature and art therapy, the juveniles expressed interest, desire and pleasure in conducting such sessions.

Thirdly in their self-reflection as a good start for overcoming any problematic situation.

The progress of such art therapies paves the way for restorative justice in Albania, as one of the efficient forms of transformation into special categories, especially in adolescents with problems with the law, reducing the possibility of recurrence or complications of the situations in which they find themselves. Time works even for those who thanks to a new opportunity can succeed in life!

\section{Acknowledgement}

This study has been carried out under the project "Restorative Actions for Transformation at Institute of Minors in Kavaja”, implemented by AHE with the support of Terre des Hommes Albania (TdH), Terre des Hommes Hungary and Albanian Foundation for Conflict Resolutions and Reconciliation of Disputes, financed by European Union. 


\section{References}

Alders, A., \& Levine-Madori, L. (2010). "The effect of art therapy on cognitive performance of Hispanic/Latino older adults." Art Therapy: Journal of the American Art Therapy Association, 27(3), 127-135.

American Art Therapy Association (2018). About Art Therapy. Available online at: https://arttherapy.org/about-arttherapy/ (Accessed June 18, 2018).

Bell, C.E. \& Robbins, S.J (2007). "Effect on art production on negative mood: A randomized, controlled trial." Art Therapy: Journal of the American Art Therapy Association, 24(2), 71-75.

Blos, P. (1962). On Adolescence. New York: The Free Press.

Case, Caroline, Dalley, Tessa. (2004). The Handbook of Art Therapy . Taylor \& Francis, 2004

Dissanayake, Ellen (1998). What is art for? London: Washington Press

Goodwin, C. J. (2005). Research in Psychology: Methods and Design. USA: John Wiley \& Sons, Inc.

Gussak, David, Virshup, Evelyn. (1997). Drawing Time: Art Therapy in Prisons and Other Correctional Settings ,Magnolia Street Publishers

Hardy, K. (1996). "Breathing room". Family Therapy Networker, 20, 3:52-61.

Hartman, Geoffrey. (1979). Preface to Deconstruction and Criticism. London; Routledge.

Huet V. (2015). Literature revieë of art therapy-based interventions for ëork-related stress. Int. J. Art Ther. 20, 66-76. $10.1080 / 17454832.2015 .1023323$

Hughes E. G., da Silva A. M. (2011). "A pilot study assessing art therapy as a mental health intervention for subfertile women." Hum. Reprod. 26, 611-615.

Jenings, Sue (ed.)(2009). Dramatherapy. Theory and practice 1. New York: Routledge.

Kaller, Xhonatan. (2001). Teori letrare, Një hyrje shumë e shkurtër. Prishtinë: Era.

Klarer, Mario. (2004). An introduction to literary studies. Bot. i 2-të. Darmstadt: Wissenschaftliche Buchgesellschaft. Liebmann, Marian. (2006). Art Therapy for Groups: A Handbook of Themes, Games and Exercises. Routledge.

Lusebrink V. B. (1990). Imagery and visual expression in therapy. New York: Plenum Press.

Macaj, Edlira T. (2019). Letërsi-Ab Initio. Tiranë: Albas.

Malchiodi, Cathy. (1998). The Art Therapy Sourcebook. Los Angeles, CA: Lowell House.

Malchiodi, Cathy. (1990). Breaking the Silence: Art Therapy with Children from Violent Homes. New York: Brunner/Mazel.

Malchiodi, Cathy. (2003). Handbook of art therapy. New York: The Guilford Press

Moon, B. (2007). The Role of Metaphor in Art Therapy: Theory, Method, and Experience. Charles C Thomas Publisher.

Naumburg, M. (1950/1973). Introduction to art therapy: Studies of the "free" art expression of behavior problem children and adolescents as a means of diagnosis and therapy. New York: Teachers College Press/Chicago: Magnolia Street

Naumburg, M. (1958). Art Therapy: Its Scope and Function in the Clinical Application of Projective Drawings. New York: Grune and Stratton.

Pound, Ezra. (1960). ABC of reading. New York: New Directions Publishing.

Robbins, A. (2000). The artist as therapist. Jessica Kingsley Publishers.

Rubin, J.A. (2001). Approaches to Art Therapy: Theory and technique. NY: Routledge.

Sacks, Oliver. The Man Who Mistook His Wife for a Hat. Touchstone, 1998, 8-22

Sommers-Flanagan, J. and Sommers-Flanagan, R. (1997) Tough Kids, Cool Counseling: User-Friendly Approaches ëith Challenged Youth. Alexandria, VA: American Counseling Association.

Shapland, Joanna. (2013). "Implications of growth: Challenges for restorative justice" . International Revieë of Victimology. 20: 111-127. Doi: 10.1177/0269758013510808

Uttley, L., Stevenson, M., Scope, A. et al. The clinical and cost effectiveness of group art therapy for people with non-psychotic mental health disorders: a systematic review and cost-effectiveness analysis. BMC Psychiatry 15, 151 (2015). https://doi.org/10.1186/s12888-015-0528-4

Wolin, Steven J,\& Wolin, Sybil. (1993).The Resilient Self: How Survivors of Troubled Families Rise Above Adversity. Villard Books. 